International journal of HIV/AIDS and Research (IJHR)

ISSN: 2379-1586

\title{
Study on the Distribution of HIV/AIDS Infections Among Age Groups Attending General Hospital Toto, Central Nigeria
}

Gyar, S.D ${ }^{1 *}$, Reuben, C. R. ${ }^{2}$ and Haruna, M. S. ${ }^{1}$

${ }^{1}$ Dept. of Biological Sciences, Nasarawa State University, Keffi, Nigeria.

${ }^{2}$ Dept of Sci. Lab. Tech., Nasarawa State Polytechnic, Lafia, Nigeria.

Review Article

\begin{abstract}
HIV/AIDS continues to remain a serious public health problem in the developing nations of the world especially in Nigeria, where about 2.9 million people are living with the infection. This study aimed at determining the seroprevalence of HIV with associated risk factors among various age groups attending General Hospital Toto, Central Nigeria. Two hundred blood samples were collected and screened for HIV using conventional methods. The observed cumulative seroprevalence of studied cases was $20.50 \%$, with patients within the age groups 51- 60 and 31- 40 having a high seropositivity while the least seropositivity was recorded among $11-20$ and $0-10$ age groups. Various risk factors examined indicated that farmers, illiterates, singles and males had high seroprevalence of 39.13\%, 32.55\%, 26.47\% and $23.37 \%$ respectively. There was no statistically significant relationship $(\mathrm{P}>0.05)$ between the various age groups and other predisposing risk factors examined. Efforts on the enlightenment campaign and orientation of the rural populace about HIV infection especially the reproductive age group are considered here as recommendation for averting or at least minimizing the scourge amongst populations of the study area.
\end{abstract}

Keywords: HIV/AIDS, seroprevalence, Toto, Nigeria

\section{*Corresponding Author:}

Gyar, S.D,

Dept. of Biological Sciences,

Nasarawa State University, Keffi, Nigeria

E-mail: silasgyar@yahoo.co.uk

Received: August 09, 2014

Accepted: August 22, 2014

Published: August 23, 2014

Citation: Gyar, S.D., Reuben, C. R. and Haruna, M. S. (2014) Study on the Distribution of HIV/AIDS Infections Among Age Groups Attending General Hospital Toto, Central Nigeria. Int J AIDS Res. 1(1), 7-10. doi: http://dx.doi.org/10.19070/2379-1586-140002

Copyright: Gyar, S.D (C) 2014. This is an open-access article distributed under the terms of the Creative Commons Attribution License, which permits unrestricted use, distribution and reproduction in any medium, provided the original author and source are credited.

\section{Introduction}

Acquired Immunodeficiency Syndrome (AIDS) caused by $\mathrm{Hu}-$ man immunodeficiency virus (HIV) is a global pandemic and is considered as the greatest public health concern in recent time [8]. In recent years, AIDS has emerged as the greatest threat to human existence. It was projected that the number of people with HIV might increase from 40 million now to 60 million by 2015 . Sub-Saharan Africa is the region that is most affected with devastating effect on life and socio-economic activities. This region harbours $68 \%$ of people living with HIV and recorded $76 \%$ of HIV related deaths in $2007[13,9,3]$.

In the first decade of the AIDs pandemic, cases were reported largely from North America, Europe, and part of Latin America, but however, in the second decade of the global pandemic, studies showed rapid increase in HIV infection in Asia, Africa and further increase in the number of people seroconverting in latin America. Although the prevalence of HIV infection is relatively stable in North America and Western Europe, success in containing the infection globally is been overwhelmed by the failure to prevent millions of new infections in Africa and Asia [16].

Nigeria has a population of over 140 million and the first case of AIDS identified in Nigeria was in 1986. HIV prevalence rose from $1.8 \%$ in 1988 to $5.8 \%$ in 2001 , dropped to $5.0 \%$ in 2003 , $5.6 \%$ in 2008 and now 3.4\%. The prevalence of HIV is highest in Rivers State (15.2\%) followed by Taraba (10.5\%), Kaduna (9.2), Nasarawa (8.1\%) and the FCT (7.5\%) [11].

Many of the countries in this region, like Zambia, Senegal, South Africa and Cote D'lvoire has developed strategies with the assistance of international communities to prevent and lower the rate of infection. Nigeria has a great deal of influence in Africa, particularly in West Africa, been the most populous country in West Africa and with 1 in 6 African being a Nigerian. Although, HIV prevalence is much lower in Nigeria than in Zambia and South Africa, it is estimated that about 2.9million Nigerians lived with HIV/AIDS in 2005. This disease, has however affected Nigerian society and its economy negatively [17].

Despite the relatively high prevalence of HIV in Nasarawa State, heterosexual behaviour of the populace, sequel to the discovery of HIV and other STI's has not changed. Some $80 \%$ of HIV infections in Nigeria are transmitted by this method.

The Nasarawa State Government has institutionalized its fight against HIV/AIDS in the aegis of Nasarawa State Action Committee on AIDS-NASACA. This, it does in collaboration with the 
Nigerian National Agency for the Control of AIDS (NACA). In spite of the huge efforts of the government, the effects of the pandemic on the life and communities in the State are still being noticed. This study was designed to determine the current status of HIV distribution with associated risk factors among various age groups attending General Hospital Toto, Nigeria with the view to generate information that may spur or stimulate planning, management, prevention and control strategies for populace.

\section{Materials and Methods}

\section{Study Population and Design}

The study population included all categories of patients across various age groups attending General Hospital Toto, central Nigeria. The study was designed to be a cross-sectional study. Ethical clearance was obtained from Hospital authority, pre counseling test was conducted on the interested candidates and their consent was sought. They were then stratified according to age group distribution using the stratified random sampling method.

A total of 200 blood samples were collected from the patients. The sample size was based on the recommended WHO guidelines which take into consideration estimates of HIV prevalence in the population surveyed [2].

\section{Methodology}

Five milliliter of blood was collected from the subjects by venepuncture. Other demographical data were recorded accordingly from each subject. The blood was allowed to clot, then centrifuged and the serum was carefully collected. The sera were all screened for HIV using rapid capillus method and Genie II, while discordant results were confirmed by the Determine $1 \& 2$ (tie-breaker) HIV kit [National Committee for Clinical Lab. Standards, (1993). All the kits were used according to manufacturer`s instructions.

\section{Results}

Out of the 200 patients were screened for HIV, 41 were HIV seropositive, giving a prevalence of $20.5 \%$. The prevalence of AIDS with respect to age distribution were $20.05 \%, 6.38 \%, 21.78 \%$, $34.28 \%, 17.64 \%$ and $50.00 \%$ respectively (Table 1). Gender prevalence of HIV as recorded from this study was $23.37 \%$ (18) $18.69 \%$ (23) for male and female respectively (Table 2). Occupational distribution of HIV indicated the prevalence of $39.13 \%$, $17.54 \%, 20.68 \%, 33.33 \%, 18.18 \%$ and $17.56 \%$ among farmers, students, businessmen, artisans, corpers, unemployed and housewives (Table 3). Table 4 and 5 indicates the prevalence of HIV with regards to educational level and marital status.

\section{Discussion}

Table 1 in this report depicts the overall prevalence of HIV/ AIDS as recorded from this study and this stands at $20.50 \%$. This is quite alarming when compared with the national prevalence of $3.4 \%$ and $8.1 \%$ in Nasarawa State [13].However, the fact that this rural hospital serves as a referral centre to many primary health care clinics in communities around and even private hospitals might be responsible for this high percentage of seropositivity. The present study, even though not representing the general population, provides a clear insight of an increasing trend of HIV seroprevalence. This finding of rising HIV seropositivity rate in patients from the study area could indicate an increasing trend of HIV transmission in the general population of this region.This finding is therefore in contrast with the claims of 'a "contained epidemic" of HIV in Nigeria' by national agencies. The impact of HIV pandemic is enormous, robbing many countries of the world of both human and natural resources [8].

A high proportion of HIV occurred among those aged 31-40 years but lowest among 11-20 years old patients. This is also presented in Table 1. The major reason for this high prevalence of HIV among patients between these age group could be attributed to the fact that they represent the most sexually active population commonly prone to risky behaviors that could expose them to HIV infection. More so, some of them though married are still promiscuous. Heterosexual act is responsible for $80 \%$ of HIV infections in Nigeria. This is in contrast to what prevail in developed countries where the spread is mainly through homosexuality and injectables [7,1].It must be mentioned here that $50 \%$ occurrence was observed amongst individuals in age 51-60. Even though this is seemingly high, it should be considered as an aberration since the study population of this age group was only 4 . This, in itself is not a satisfactory statistical number sufficient to generate a dependable finding.

The age specific distribution of HIV prevalence as recorded in this study differs from the results obtained [5,8] where they obtained higher prevalence in younger individuals. The lower prevalence recorded among younger patients agrees with the works of $[7,10]$. These age groups might not really be so-exposed. Some of them might have acquired the infection through vertical transmission. The potential consequences of undiagnosed HIV in pregnancy can be tragic. Vertical transmission among other things is responsible for about $10 \%$ of HIV infection in Nigeria. National Institute of Health, United States' clinical trial showed that antiretroviral medication provided to HIV positive pregnant women during pregnancy, labour and delivery and to the newborn during the first weeks of life dramatically reduced the risk of vertical transmission of HIV [4]. Other studies actually confirmed a reduction in transmission from $25 \%$ to $8 \%$ or even less [12].

Table 1. HIV distribution among different age groups

\begin{tabular}{|l|l|l|l|}
\hline Age & No. Tested & No. Positive & $\%$ positive \\
\hline $0-10$ & 19 & 4 & $21.05 \%$ \\
\hline $11-20$ & 47 & 3 & $6.38 \%$ \\
\hline $21-30$ & 78 & 17 & $21.78 \%$ \\
\hline $31-40$ & 35 & 12 & $34.28 \%$ \\
\hline $41-50$ & 17 & 3 & $17.64 \%$ \\
\hline $51-60$ & 4 & 2 & $50.00 \%$ \\
\hline Total & 200 & 41 & $20.50 \%$ \\
\hline
\end{tabular}

Table 2. HIV distribution by gender

\begin{tabular}{|l|l|l|l|}
\hline Sex & No. Tested & HIV Positive & $\%$ Positive \\
\hline Male & 77 & 18 & $23.37 \%$ \\
\hline Female & 123 & 23 & $18.69 \%$ \\
\hline Total & 200 & 41 & $20.50 \%$ \\
\hline
\end{tabular}


Table 3. HIV distribution by occupation

\begin{tabular}{|l|l|l|l|}
\hline Occupation & No:Tested & HIVPositive & $\%$ Positive \\
\hline Farmer & 23 & 9 & $39.13 \%$ \\
\hline Students & 57 & 10 & $17.54 \%$ \\
\hline Businessmen & 29 & 6 & $20.68 \%$ \\
\hline Artisans & 3 & 0 & $0.00 \%$ \\
\hline Corpers & 3 & 1 & $33.33 \%$ \\
\hline Unemployed & 11 & 2 & $18.18 \%$ \\
\hline Housewife & 74 & 13 & $17.56 \%$ \\
\hline Total & 200 & 41 & $20.50 \%$ \\
\hline
\end{tabular}

Table 4. HIV distribution by level of education

\begin{tabular}{|l|l|l|l|}
\hline Levelofeducation & No.Tested & HIVpositive & \%Positive \\
\hline Illiterate & 43 & 14 & $32.55 \%$ \\
\hline Primary & 37 & 8 & $21.62 \%$ \\
\hline Secondary & 74 & 8 & $10.18 \%$ \\
\hline Tertiary & 42 & 10 & $23.80 \%$ \\
\hline Qur'anic & 4 & 1 & $25.00 \%$ \\
\hline Total & 200 & 41 & $20.50 \%$ \\
\hline
\end{tabular}

Table 5: HIV distribution by marital status

\begin{tabular}{|l|l|l|l|}
\hline Maritalstatus & No.Tested & No.Positive & $\%$ Positive \\
\hline Single & 68 & 18 & $26.47 \%$ \\
\hline Married & 132 & 23 & $17.42 \%$ \\
\hline Total & 200 & 41 & $20.50 \%$ \\
\hline
\end{tabular}

Results in Table 2 show that the male gender has $23.33 \%$ occurrence ahead of the female gender with $18.69 \%$. This might not be unassociated with the roving and randy nature of some men who might be infected and thereby distributing the virus rampantly.

With respect to occupation and level of education, Table 3 shows farmers and illiterates had the highest prevalence of HIV from this study. This might be due to low access to health care facilities in remote or rural areas. Also, there is a higher rate of promiscuous activities and polygamous life style within rural dwellers whose primary occupation is farming, therefore making this a vulnerable group.

The prevalence rate of study population based on educational status is shown on 4 while Table 5 is on marital status. [6] in a study in Zimbabwe found a marked decline in HIV prevalence rates in 15-19 year old males and females with a medium to higher-level education, compared to increases among those with lower educational levels. Education is a central tool required to reduce the social and economic vulnerability of women. Evidence shows that education aimed specifically at girls and women can slow and even reverse the spread of HIV. Education does this by arming women with valuable life and decision-making skills - which all contribute to poverty reduction, gender equality, personal empowerment, and increased awareness of human rights issues. Women can then pass on to their children, partners, and friends these valuable skills and knowledge. Education enables women's economic independence by delaying marriage, proactive family planning, and by increasing their ability to engage in paid work to support themselves and their families $[14,15]$.

The prevalence of HIV in relation to gender and marital status as recorded in this study were high in males and singles. This is in consonance with the findings of [10] who recorded a high HIV prevalence in male in north central Nigeria. Most males though married still indulges in extramarital sex which exposes them to HIV infection. Also, most singles are commonly prone to risky behaviors that could expose them to HIV infection. These behaviors include unprotected sex and sharing of unsterilized materials such as surgical blades, Razor blades, needle and scissors etc. which they probably could not afford to buy and where HIV preventive measures are not well understood [5].

\section{Conclusion}

The prevalence rate observed in this study simply indicates that it is high among study population.. This high seroprevalence of HIV shows that much needs to be done in terms of prevention of this infection. It is obvious from the results of this study that a high rate of HIV infection has been observed in this community. Apart from the increasing HIV prevalence the most affected age group constitutes the most productive sector of the nation. The public health implication of both infections on families, communities and indeed the whole country will be enormous and cannot be over emphasized. It is therefore suggested that government should double its efforts on the enlightenment campaign and orientation of the rural populace about HIV infection especially the reproductive age group. This report recommends this approach for government in order to reduce the occurrence of this infection.

\section{References}

[1]. Akanni, C.I, Ojule, A.C, Opurum, H.C., John, C.T. (2006) Seroprevalence of HIV antibodies in pregnant women in Port Harcourt, Nigeria. Nig. J. 
Med., 15(1):44-8.

[2]. Federal Ministry of Health (FMOH) (2005). National Sentinel Surveillance Survey Technical Report. Federal Ministry of Health, Abuja, Nigeria.

[3]. Frederickson, J. and Kanabus, A. (2005). HIV and AIDS in Africa. http://usf524.mail.yahoo.com

[4]. Jaiyesimi, R.A.K. (2000) HIV screening in Pregnancy. Sexual Health Matters, 1(4):78-9.

[5]. Joshua, I. A. Sabitu, K. and Ogboi, J. S. (2006) Socio demographic characteristics and Risk factors for HIV/AIDS transmission among inmates of Convict prison Kaduna, Nigeria. Nig. J. Sci. Res. (in press).

[6]. Kelly, M. J. (2000) The Encounter Between HIV/AIDS and Education. Harare, Zimbabwe: UNESCO, Sub-Regional Office for South Africa.

[7]. Mehrontra, R., Pourush, S., Bhargara, A., Varma, M., and Ghosh, U.K. (2005) Sero-prevalence of HIV in antenatal women. J. Obstet. Gynecol., 55(4):333-5.

[8]. Muhammad, T., Auwal, U., Baba, M.M. and Thilza, I.B. (2010) HIV Infection among Male Prison Inmates in Abuja, Nigeria. Nature and Science, 8(6): 92-94

[9]. Ogunkolo, O. F., Adenaike, F.A., Amballi, A.A, Olukoya, T. (2006) Prevalence of HIV positive blood donors among screened volunteers who satisfied the criteria for blood donation in a semi-urban Nigeria population. Afr J Biotechnol., 5(7):553-4.

[10]. Olajubu, F. A., Osinupebi, O. A., Deji-Agboola, M. and Jagun, E.O. (2009)

[11]. Seroprevalence of HIV Among Blood Donors, Antenatal Women and Other Patients in a Tertiary Hospital in Nigeria. Braz. J. Inf. Dis., 13(4):280-283.

[12]. Rivers has highest HIV/AIDS rate - FG. Nigeria Punch, December 8, 2013, www.punch.com.ng

[13]. Rogers, M.A., Motenson, L.M., Moseley, R.R. (1995) Reducing the risk of perinatal HIV Transmission through zidovudine therapy: Treatment recommendation and implications. J. American Med. Women's Ass., 50(324):7882 .

[14]. UNAIDS/WHO (2007) Sub Saharan Africa, HIV and AIDS statistic. Report on the global epidemic. www.avert.org

[15]. UNAIDS (2000) Report on the Global HIV/AIDS Epidemic. Geneva.

[16]. Gregson, S., Waddell, H., and Chandiwana, S. (2001) School Education and HIV Control in Sub-Saharan Africa: From discourse to harmony? J. Intl. Dev., 13: 467-485

[17]. WHO, UNAIDS and UNICEF, (2008) Towords Universal access., scaling up priority HIV/AIDS interventions in the health sectors. Progress report. April, Geneva.ISSBN9789241595391.

[18]. World losing fight against AIDS - Nigeria Tribune 23 November, 2007 www.tribune.com.ng HIV and AIDS in Nigeria (2007) http://www.avert.org 